\title{
Chlorine Dioxide Oxidations of Tyrosine, N-Acetyltyrosine, and Dopa
}

Michael J. Napolitano, Brandon J. Green, Jeffrey S. Nicoson, and Dale W. Margerum*

Department of Chemistry, Purdue University, West Lafayette, IN 47907-2084, USA

Supporting Information 


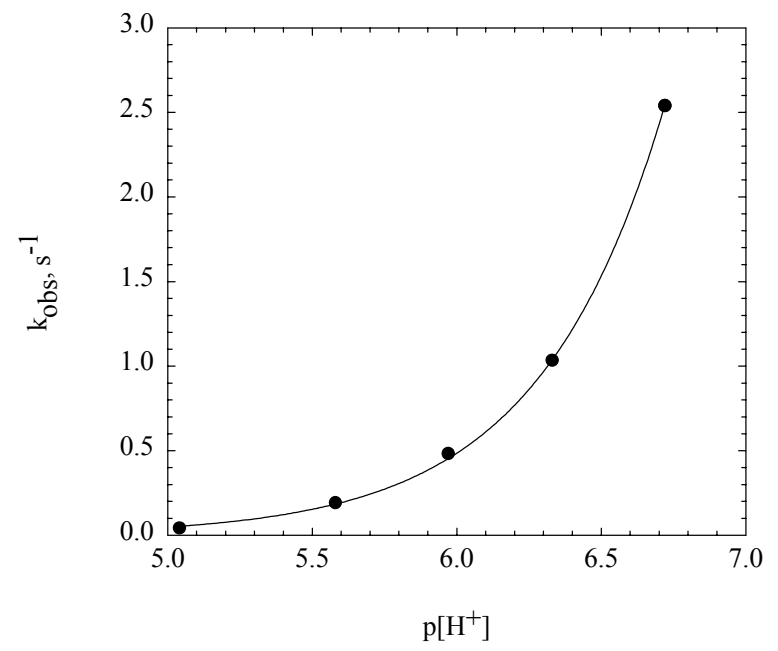

Figure S1. Observed first-order rate constants (dopachrome formation) vs. $\mathrm{p}\left[\mathrm{H}^{+}\right]$at 490 nm. First order rate constant for the cyclization of dopaquinone is estimated to be 249(2) $\mathrm{s}^{-1}$ using the $\mathrm{pK}_{\mathrm{a}}$ of the amino group of dopa. Conditions: [Tyr] $2.00 \mathrm{mM},\left[\mathrm{ClO}_{2}\right] 0.187$ $\mathrm{mM},\left[\mathrm{PO}_{4}\right]_{\mathrm{T}} 25 \mathrm{mM}, \mu=1.0 \mathrm{M}\left(\mathrm{NaClO}_{4}\right)$, and a pathlength of $0.962 \mathrm{~cm}$. 


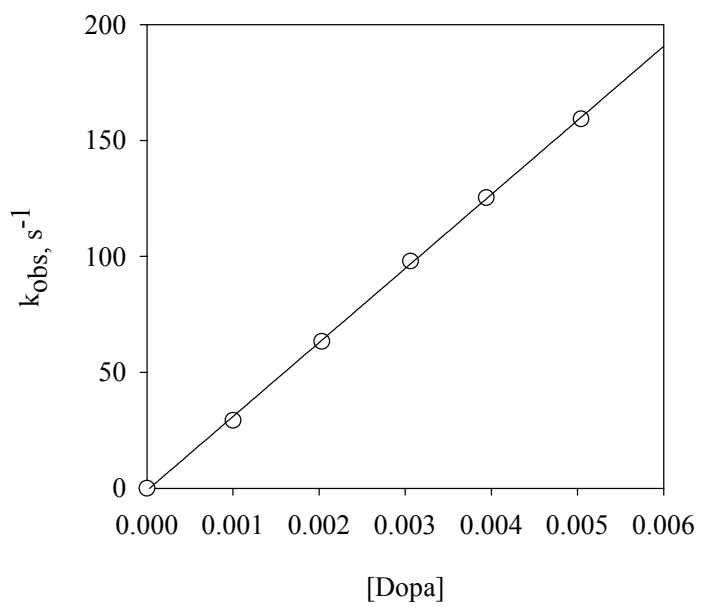

Figure S2. First-order rate constants for the loss of $\mathrm{ClO}_{2}$ vs [dopa]. Conditions: $\left[\mathrm{ClO}_{2}\right]$ $=0.20 \mathrm{mM}, \mathrm{p}\left[\mathrm{H}^{+}\right] 4.27,[\mathrm{OAc}]_{\mathrm{T}}=0.200 \mathrm{M}, \mu=1.00 \mathrm{M}\left(\mathrm{NaClO}_{4}\right), \lambda=359 \mathrm{~nm}, 25.0^{\circ} \mathrm{C}$. 


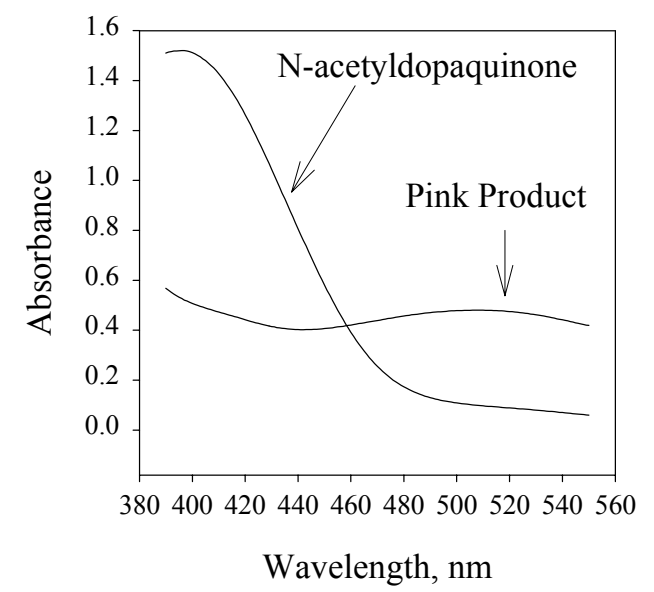

Figure S3. UV-vis spectra of N-acetylquinone and pink product formed upon standing. Conditions: $\left[\mathrm{ClO}_{2}\right] 1.00 \mathrm{mM},[\mathrm{NAT}] 10.0 \mathrm{mM}, \mathrm{p}\left[\mathrm{H}^{+}\right] 5.48,\left[\mathrm{PO}_{4}\right]_{\mathrm{T}} 0.100 \mathrm{M}, \mu=1.0 \mathrm{M}$ $\left(\mathrm{NaClO}_{4}\right), 5 \mathrm{~cm}$ cell, $25^{\circ} \mathrm{C}$. 


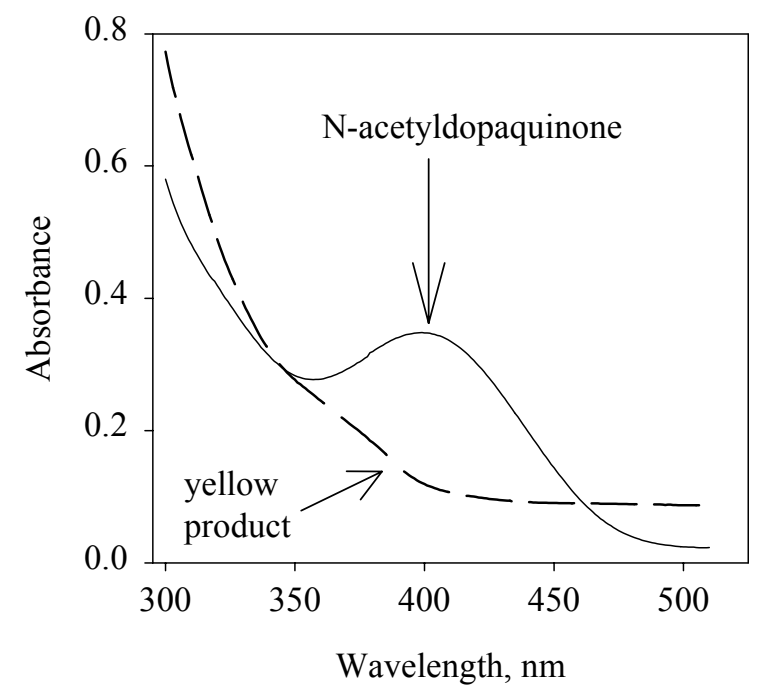

Figure S4. UV-vis spectra of N-acetylquinone and yellow product formed upon standing. Conditions: $\left[\mathrm{ClO}_{2}\right] 2.00 \mathrm{mM},[\mathrm{NAT}] 1.0 \mathrm{mM}, \mathrm{p}\left[\mathrm{H}^{+}\right] 5.69,\left[\mathrm{PO}_{4}\right]_{\mathrm{T}} 0.100 \mathrm{M}, \mu=$ $1.0 \mathrm{M}\left(\mathrm{NaClO}_{4}\right), 1 \mathrm{~cm}$ cell, $25^{\circ} \mathrm{C}$. 